\title{
Estudo da técnica da sindesmoplastia extra-articular com fascia lata autógena. Modelo em cães
}

\section{Study of the extra articulate syndesmoplasty technique with autogenous fascia lata. A model in dogs}

Manoel luiz Ferreira 1; Alberto Schanaider 2; Paulo César Silva ${ }^{3}$; Antônio Victor de Abreu4; Andrei Ferreira Nicolau Costa; Jalene Meira Braga ${ }^{6}$; Raul Rousso Filho ${ }^{6}$; Lara de Paula M. Pereira ${ }^{7}$

\section{RE S U M O}

\begin{abstract}
Objetivo: Avaliar a eficácia da técnica extra-capsular para o tratamento de ruptura do ligamento cruzado anterior em cães. Métodos: Foi realizada a reparação cirúrgica extra-articular, sem artrotomia do ligamento cruzado anterior, com a utilização da fáscia lata autógena para estabilização da articulação do joelho em seis animais que apresentaram claudicação grave e movimento de gaveta positivo. Resultados: A técnica cirúrgica extra-articular foi eficaz com boa estabilização articular e evolução satisfatória. Conclusão: A via extra capsular com uso da fáscia lata para correção da ruptura do ligamento cruzado anterior mostrou-se útil haja vista tratar-se de um procedimento simples e de rápida execução, causando o mínimo dano tecidual e recuperação pós-operatória eficiente.
\end{abstract}

Descritores: Modelos animais. Ligamento cruzado anterior. Traumatismos do joelho. Fáscia lata.

\section{INTRODUÇÃO}

O ligamento cruzado anterior ou cranial (LCA) tem a função de limitar os movimentos da articulação fêmorotíbio-patelar (FTP) e impedir o deslocamento cranial da tíbia em relação ao fêmur, a rotação interna excessiva da tíbia e a hiperextensão articular. Forças excessivas aplicadas a qualquer um desses movimentos podem resultar na lesão do referido ligamento'.

A ruptura do ligamento cruzado anterior, completa ou parcial, é causa comum da claudicação no membro pélvico dos cães². De uma maneira geral, o exame clínico compreende a avaliação e o registro dos seguintes parâmetros: claudicação, qualidade de apoio, grau de atrofia muscular, presença ou ausência do movimento de gaveta, deslocamento cranial da tíbia em relação ao fêmur, rotação interna da tíbia, sensibilidade à palpação da articulação, crepitação e espessamento da cápsula articular, além do teste de compressão tíbiali,4.

O tratamento da ruptura do LCA abrange técnicas cirúrgicas, com acesso intra ou extra-articulares. As intraarticulares utilizam material autógeno, alógeno ou sintéti$\mathrm{CO}^{5}$, enquanto as extra-articulares alteram as relações entre as estruturas anatômicas peri-articulares, mimetizando a função desempenhada pelo LCA ${ }^{6,7}$. A escolha da técnica depende exclusivamente do cirurgião e que levará em consideração o peso do animal, seu grau de atividade e o tem-

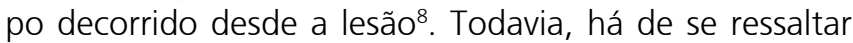
que o acesso intra-articular resulta em trauma cirúrgico de maior monta.

O presente estudo tem por objetivo descrever uma técnica de correção cirúrgica sem artrotomia para cães portadores de ruptura de LCA do joelho, eficiente, simples, de fácil execução e baixo custo, e que permite a recuperação da função do membro em curto período de tempo póscirúrgico.

\section{MÉTODOS}

Este estudo foi aprovado pelo Comitê de Ética para o Uso de Animais de Laboratório em Pesquisa da Faculdade de Medicina da UFRJ.

Seis cães (Canis familiaris) de diferentes linhagens, adultos (de oito a nove anos), peso compreendido entre 9,6 e 19,7 kg, previamente diagnosticados com ruptura do LCA, foram operados. O exame clínico pré-operatório, em todos os animais, revelou sinal de gaveta positivo para o movimento na articulação do joelho, deslocamento cranial e rotação interna da tíbia. 
Nos exames radiológicos prévios não foi possível identificar o deslocamento cranial da tíbia e nem a presença de corpo livre intra-articular.

Foi avaliado, ainda no pré-operatório, o grau de claudicação no membro posterior, de acordo com uma escala crescente de gravidade ${ }^{9}$ (Tabela 1).

O pré, trans e pós-operatório foram realizados no Centro Médico Veterinário Tijuca, cidade do Rio de Janeiro, RJ, Brasil.

Foram observados, para todos os cães, o jejum prévio para sólidos de 12 horas e a restrição hídrica quatro horas antes da operação.

O pré-anestésico compreendeu a administração de Fentanil $(5 \mathrm{mcg} / \mathrm{kg})$, por via intravenosa, e de Ringer lactato. Seguiu-se à tricotomia do campo cirúrgico e da região lombo-sacra, esta para a realização de anestesia epidural com lidocaína $2 \%$ com vasoconstritor $(5 \mathrm{mg} / \mathrm{kg})$, aduzida de morfina $1 \%(0,05 \mathrm{mg} / \mathrm{kg})$. A indução anestésica foi efetuada com Propofol $1 \%(10 \mathrm{mg} / \mathrm{kg})$ e a manutenção com sevoflurano e oxigênio à 100\%.

Os animais foram imobilizados na mesa cirúrgica, em decúbito lateral esquerdo ou direito, conforme o lado da lesão e foram observados todos os cuidados de anti-sepsia e assepsia.

A técnica operatória constou de incisão de pele e tecido subcutâneo, no sentido longitudinal, lateralmente à articulação fêmoro-tíbio-patelar, desde o terço cranial do fêmur até o terço proximal da tíbia. Rebateu-se uma faixa da fáscia lata com largura de aproximadamente $1,5 \mathrm{~cm}$, e que foi liberada na sua inserção proximal até a sua porção distal, permanecendo íntegra na altura da tuberosidade da tíbia (Figura 1). Prosseguiu-se com a sutura da parte pediculada do neo-tendão proveniente da fáscia lata no ligamento patelar e, em seguida, transpassou-se totalmente o neo tendão sob a fabela lateral com auxilio de uma pinça hemostática curva (Figura 2). Realizou-se uma segunda rafia sob pressão envolvendo o neo tendão ao músculo gastrocnêmio em sua porção cranial e direcionou-se a extremidade deste neo tendão para sutura no ligamento patelar sob tensão (Figura 3). Todas as suturas até este tempo cirúrgico foram efetuadas com fio monofilamentar de náilon 2-0.

Obedeceu-se rigorosa hemostasia e na síntese dos planos anatômicos, para a correção do defeito causado pela retirada da faixa da fáscia lata utilizou-se o fio poliglicólico 30 com pontos simples (Figura 4). Para a síntese da pele optou-se pelo fio monofilamentar de náilon 3-0.

O tratamento pós-operatório constou de: bandagem/tipóia de Ehmer por 10 dias; aplicação de meloxican $0.1 \mathrm{mg} / \mathrm{kg}$ a cada 24 horas, por via intramuscular, durante três dias; administração de penicilina benzatina $40.000 \mathrm{Ul} / \mathrm{kg}$, via intramuscular a cada 48 horas, no total de três aplicações; curativo diários da ferida cirúrgica com aplicação tópica de álcool $70 \mathrm{GL}$, até a retirada dos pontos de pele no $14^{\circ}$ dia de pós-operatório.

Os exames clínicos foram feitos através da inspeção e palpação da região fêmoro-tibio-patelar para realizar o teste de gaveta, sensibilidade e verificação da deambulação aos 14, 30, 180 e 240 de pós-operatório.
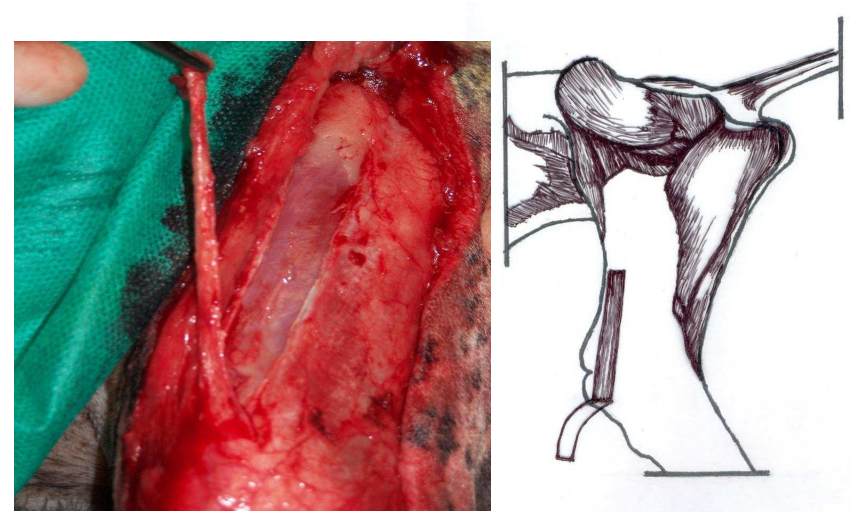

Figura 1 - Confecção de faixa da fascia lata, com esquematização do procedimento.
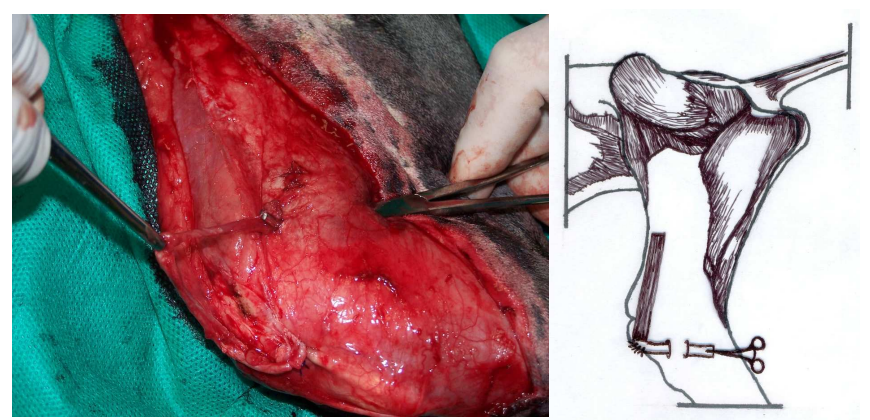

Figua 2 - $\quad$ Fixação e passagem da fascia lata com uso de pinça hemostática e sua correspondente esquematização.


Figura 3 - Finalização da sutura da fascia lata no ligamento patelar, de acordo com a demonstração esquemática ao lado.
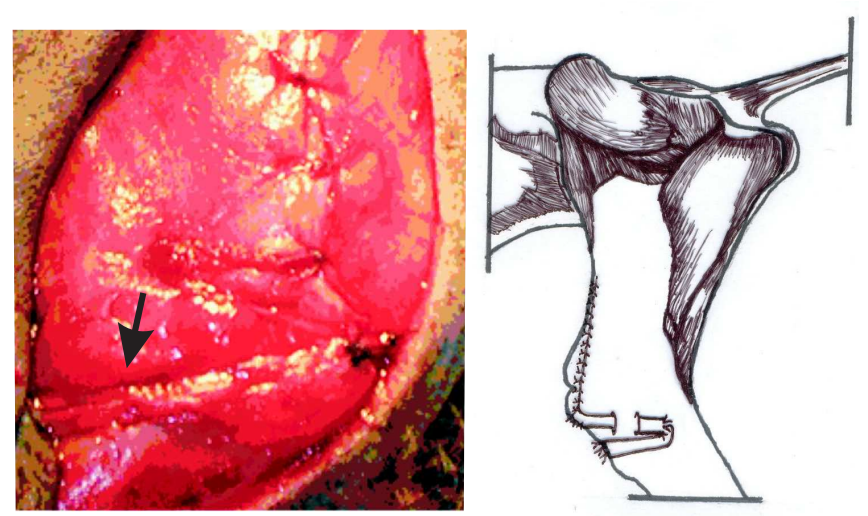

Figura 4 - Sutura do defeito da fascia lata, observando-se a sua fixação (seta). 
Em cada um destes períodos, os animais foram reavaliados e classificados quanto aos critérios apresentados na tabela 1.

Para avaliação estatística utilizaram-se os testes de Tukey, e t de Student, para a comparação dos diferentes tempos de observação no mesmo animal e para a análise entre as médias dos diversos tempos evolutivos para o grupo de animais estudados. O teste de Wilcoxon também foi utilizado para avaliar os graus de claudicação entre o pré-operatório e 14 dias de evolução. O grau de significância estabelecido para os dois testes estatísticos foi de $5 \%(p<0,05)$.

\section{RESULTADOS}

A avaliação dos animais e de seu grau de claudicação no pré-operatório, de acordo com os critérios contidos na tabela 1, evidenciou, em um cão, claudicação esporádica ao caminhar, e, nos demais, claudicação acentuada ou incapacidade de utilização do membro comprometido pela lesão (Tabela 2).

Para a confecção do retalho de fascia lata pediculado utilizou-se uma estrutura anatômica, com características tendinosas.

A fabela proporcionou maior apoio e firmeza do neo tendão e angulação perfeita para as suturas ao músculo gastrocnêmio e ao ligamento patelar.

O desenvolvimento do processo cicatricial ocorreu sempre por primeira intenção, com a retirada dos pontos de pele no $14^{\circ} \mathrm{dia}$

Avaliação quanto ao grau de claudicação dos animais no pós-operatório encontra-se descrita na tabela 3.

O teste de Wilcoxon, para avaliação dos graus de claudicação entre o pré-operatório e 14 dias mostrou recuperação significativa $(p=0,0313)$.
No que tange à claudicação, os resultados estatísticos evidenciaram, a partir do $30^{\circ}$ dia de pós-operatório, ausência de variações evolutivas significantes nos diversos períodos estudados para cada animal e também entre as médias de cada período, per si $(p<0,05)$. (Figura 5).

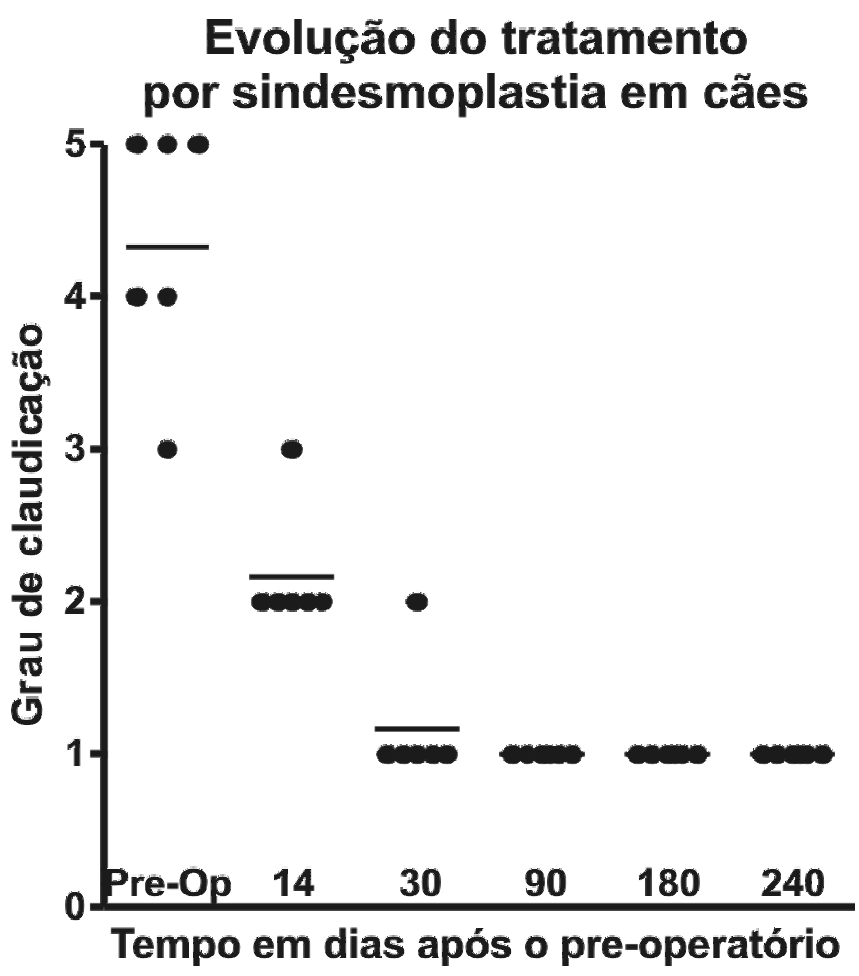

Figura 5 - Evolução do tratamento por sindesmoplastia: comparação dos graus de claudicação nos diversos tempos pós-operatórios.

*Pré-op vs 14 dias $=p<0,05$

Tabela 1 - Classificação da deambulação de cães.

\section{Grau Critério}

1 Claudicação ausente; apoio completo do membro com o animal em estação ou durante atividade física.

2 Claudicação discreta após exercício ou decúbito prolongado.

3 Claudicação esporádica ao caminhar ou correr, com alívio do peso sobre o membro operado, inclusive em estação.

4 Claudicação constante ao caminhar e não apoio do membro ao correr; apoio incompleto em posição ortostática.

5 Apoio incompleto ou ausente durante atividades físicas ou em estação.

Fonte: Adaptado de Muzzi (2003).

Tabela 2 - Dados gerais pré-operatórios.

\begin{tabular}{lccrc}
\hline Raça & Sexo & $\begin{array}{c}\text { Idade } \\
\text { (Anos) }\end{array}$ & $\begin{array}{r}\text { Peso } \\
\text { (Kg) }\end{array}$ & $\begin{array}{c}\text { Claudicação } \\
\text { (Grau) }\end{array}$ \\
\hline Poodle & Fêmea & 9 & 9,6 & 5 \\
Srd* & Macho & 8 & 13,4 & 5 \\
Labrador & Macho & 9 & 19,9 & 4 \\
Poodle & Macho & 8 & 12,3 & 4 \\
Boxer & Fêmea & 9 & 19,7 & 5 \\
C. Spaniel & Macho & 9 & 14,6 & 3 \\
\hline
\end{tabular}

${ }^{*}$ SRD- Sem raça definida.
Tabela 3 - Avaliação dos animais submetidos à sindesmoplastia.

\begin{tabular}{|c|c|c|c|c|c|}
\hline \multirow[t]{2}{*}{ Animal } & \multicolumn{5}{|c|}{ Grau de Claudicação } \\
\hline & 14dias & 30 dias & 90dias & 180 dias & 240 dias \\
\hline 1 & 2 & 1 & 1 & 1 & 1 \\
\hline 2 & 2 & 1 & 1 & 1 & 1 \\
\hline 3 & 3 & 2 & 1 & 1 & 1 \\
\hline 4 & 2 & 1 & 1 & 1 & 1 \\
\hline 5 & 2 & 1 & 1 & 1 & 1 \\
\hline 6 & 2 & 1 & 1 & 1 & 1 \\
\hline
\end{tabular}


Todos os seis animais examinados nos períodos determinados de pós-operatório não apresentaram movimento de gaveta e ou dor a palpação na região da articulação do joelho, com ótima evolução já aos 90 dias, ou seja, sem claudicação e demonstrando o apoio completo do membro tanto em posição estática, como durante a atividade física.

\section{DISCUSSÃO}

A anatomia do joelho é complexa e lesões ligamentares nesta topografia, na espécie humana e nos animais podem trazer limitações relevantes e instabilidade à movimentação. O LCA é a principal estrutura da estabilização da translação anterior da tíbia em relação ao fêmur, auxiliado por ligamentos capsulares, pelos meniscos, além da musculatura flexora.

O diagnóstico de ruptura do ligamento cruzado em cães é baseado na história clínica de aparecimento de claudicação e presença do movimento de gaveta positivo na região da articulação fêmoro-tíbio-patelar ${ }^{10}$, sinais estes encontrados nos animais operados. O movimento de gaveta cranial é um sinal patognomônico de ruptura do LCA ${ }^{11}$. O estudo radiológico simples não possibilita a detecção do ligamento rompido, mas pode identificar a presença do sinal da gaveta (deslocamento anterior da tíbia) ou até de fragmento ósseo intra-articular no caso de avulsão do LCA ${ }^{12}$. Outros métodos de imagem mais sofisticados, a exemplo da tomografia computadorizada e da ressonância magnética permitem melhor acurácia diagnóstica, entretanto seu uso é restrito em cães, em face da infra-estrutura necessária e dos custos para execução do exame.

O tratamento cirúrgico tem como objetivo principal a estabilização funcional do joelho. Diversas técnicas para tratamento de lesões ligamentares do joelho têm sido utilizadas nos últimos anos e compreendem acessos extra ou intra-articulares com uso de tecido autólogo, ou material sintético ${ }^{13}$.

As técnicas extra-articulares conferem estabilidade devido ao espessamento dos tecidos periarticulares, resultante do processo inflamatório causado pelo procedimento cirúrgico ${ }^{4,14}$. Exceções desta técnica extra-articular são: a transposição da cabeça da fíbula, na qual o ligamento colateral lateral estabiliza a articulação; a osteotomia de elevação do platô tibial, na qual o realinhamento do deste platôl neutraliza o movimento cranial da tíbia ${ }^{6,7,15,-18,}$ e a transposição cranial do tendão poplíteo, onde este tendão será responsável pela estabilidade articular ${ }^{15}$.

O aloenxerto de tendão patelar congelado tem sido preconizado em cães que foram submetidos à operação com acesso intra-articular com resultados satisfatórios ${ }^{19}$. Outras técnicas utilizam material heterólogo, a exemplo do retalho do centro frênico de equino tratado com glicerina ${ }^{10,20}$. A fáscia lata autóloga, como substituto do LCA, tem sobressaído, ao longo do tempo, sendo o enxerto mais amplamente utilizado em cães ${ }^{21-23}$.

A fascia lata humana pode resistir, em testes de laboratório, até $74,8 \mathrm{~kg}$ de tração, valor este maior do que os músculos semitendinoso, com 38kg, e grácil com 36 kg e também do ligamento cruzado anterior, que tem resistência à tração de $51,2 \mathrm{~kg}$. Assim, a primeira opção para a substituição do LCA reside na escolha da fascia lata ${ }^{24}$. Porém, alguns autores advogam o seu uso para o reforço nos casos em que haja grande instabilidade ântero-lateral ${ }^{25}$. Em anima nobile, a via artroscópica é a mais utilizada para correção cirúrgica da ruptura do LCA. Os enxertos autólogos de eleição são os do terço médio do tendão patelar e dos tendões semitendinoso e grácil. Estes são fixados no fêmur através de botão de titânio e fita poliéster e na tíbia mediante uso de parafuso de titânio com arruela, para osso esponjoso ${ }^{26,27}$.

A abordagem operatória extra-articular com o uso da fáscia lata foi eficaz para a realização da sindesmoplastia. A escolha da largura depende da técnica escolhida e do peso do animal submetido à operação. Faixas ou tiras com $1 \mathrm{~cm}$ de largura são recomendadas em animais com até 20 $\mathrm{kg}^{4}$. Em animais com massa corpórea entre 15,3 e 33 kg é aconselhável a utilização de uma tira de largura aproximada de 1,5 a 2,5 cm ${ }^{28}$. A opção neste estudo foi por uma faixa de largura de $1,5 \mathrm{~cm}$, pois os animais não ultrapassaram $20 \mathrm{~kg}$. A liberação da faixa da fáscia lata junto à sua inserção proximal até à sua porção distal, permanecendo íntegra na altura da tuberosidade da tíbia, foi suficiente para realizar a fixação da articulação, em conformidade com o relato de outros autores ${ }^{4,29}$.

Um aspecto relevante da técnica em cães foi à localização da fabela lateral, ao redor da qual o enxerto foi passado, após prévia aplicação de outro fio de náilon-0, para guiá-lo. O enxerto foi suturado nele mesmo, na região próxima à crista tibial com fio de náilon 2-0 em ponto simples e separados ${ }^{29}$. A técnica desenvolvida neste estudo consistiu em suturas com fios de náilon 2-0 sob pressão, no ligamento patelar, inserção do gastrocnêmio, após passagem pela fabela lateral e ligamento patelar.

No cão há fabelas laterais e mediais, as quais estão localizadas nos côndilos respectivos de cada fêmur. Devido à ausência da fabela no homem, seria possível a aplicação de uma prótese com utilização de parafuso para osso esponjoso no côndilo lateral do fêmur, criando, desta maneira, uma estrutura para reduzir a pressão restante sobre o retalho da fascia lata, os músculos e os ligamentos envolvidos nesta técnica cirúrgica

Recomenda-se que o defeito produzido na fáscia lata seja suturado com poliamida em padrão interrompido simples, ou com fio monofilamentar de náilon 3-0, em pontos de Kirschner. Atenção deve ser prestada à síntese do tecido subcutâneo, objetivando a redução do espaço morto, se necessário, com o uso de fios absorvíveis ${ }^{29}$.

Observa-se, na literatura sobre o assunto, que animais tratados cirurgicamente, sem artrotomia, foram os que apresentaram melhores resultados no pós-operatório, apoiando o membro, normalmente, decorridos 14 a 30 dias do procedimento cirúrgico ${ }^{4}$, a exemplo do que foi observado neste experimento em especial a partir do $30^{\circ}$ dia.

O tratamento pós-operatório constitui um dos fatores responsáveis pelo êxito do ato cirúrgico. O uso de antibiótico é recomendado. Os protocolos variam de acor- 
do com a conduta dos autores. Nos cães há esquemas com ampicilina anidra na dose de $20 \mathrm{mg} / \mathrm{kg}$ em intervalos de oito horas durante sete dias e rifamicina tópica, três vezes ao dia durante oito dias ${ }^{4}$. Outra opção consiste da associação do cetoprofeno $2,2 \mathrm{mg} / \mathrm{kg}$ a cada 24 horas ou do caprofeno $2,2 \mathrm{mg} / \mathrm{kg}$ a cada 12 horas com spray à base de rifamicina no curativo da ferida, até a completa cicatrização ${ }^{28}$. Para a analgesia pode ser administrada flunixina meglumina $1 \mathrm{mg} / \mathrm{kg}$ via intramuscular, a cada 24 horas, por três dias ${ }^{29}$.

O protocolo utilizado no pós-operatório dos seis cães consistiu da aplicação de penicilina benzatina 40.000 $\mathrm{UI} / \mathrm{kg}$, via intramuscular, a cada 48 horas, no total de três doses e do uso do analgésico e antiinflamatório meloxican $1 \mathrm{mg} / \mathrm{kg}$ a cada 24 horas por via intramuscular durante três dias, além do curativo da ferida cirúrgica com degermação tópica diária de álcool $70 \mathrm{Gl}$.

No período pós-operatório vários parâmetros podem ser analisados no membro operado, dentre os quais sobressaem: a observação do grau de claudicação, a qualidade de apoio e o retorno à marcha normal, a crepitação ou sensibilidade à palpação, a ausência do movimento de gaveta, a presença de atrofia muscular, a instabilidade articular, o espessamento periarticular ${ }^{4}$, o apoio do membro e a reação ao implante ${ }^{10,20,29}$. A avaliação clínica realizada nos animais após a operação baseou-se, principalmente, nos quatro primeiros parâmetros supracitados. Com 14 dias melhoras significantes foram observadas na comparação com o pré-operatório. Obviamente o peso dos animais pode ter exercido pequena interferência quanto à resposta mediata à operação. Porém, a ausência de claudicação já aos 30 dias, em cinco dos cães operados e completa aos 90 dias para todos os animais, demonstrou a eficácia do tratamento realizado, dentro de um prazo considerado muito satisfatório para recuperação neste tipo de lesão ligamentar.

A técnica utilizada pode apresentar as seguintes vantagens, quando comparada à abordagem intra-articular, dentre as quais: o menor tempo cirúrgico, a redução dos custos operacionais do ato operatório, a mobilização precoce pela redução da dor pós-operatória, e a ausência de trauma decorrente do acesso intracapsular e suas consequências a longo prazo.

Conclui-se que a técnica cirúrgica utilizada demonstrou ser procedimento terapêutico eficaz para a estabilização da articulação do joelho em cães, portadores de ruptura do ligamento cruzado anterior, com recuperação integral já aos três meses de evolução pós-operatória.

\title{
A B S S T R A C T
}

\begin{abstract}
Objetive: To evaluate extra-capsular technique for the treatment of the anterior cruciate ligament rupture, in dogs. Methods: It was performed an extra-articulate surgery without arthrotomy of the anterior cruciate ligament by using a strip of the autogenous fascia lata for stabilization of the knee joint in six animals which had severe claudication and drawer movement sign positive. Results: The extra articulate technique was effective with good knee stabilization and satisfactory outcome. Conclusion: The use of the fascia lata with an extra capsular technique to fix the rupture of the anterior cruciate ligament seems to be useful once it is a simple and rapid procedure with minimum tissue damage and efficient postoperative recovery
\end{abstract}

Key Words: Models, Animal. Anterior cruciate ligament. Knee injuries. Fascia lata.

\section{REFERENCIAS}

1. Arnoczky SP. Pathomechanics of cruciate ligament and meniscal injuries. In: Bojrad MJ. Disease mechanics in small animal surgery. $2^{\text {nd }}$ ed. Philadelphia: Lea \& Febiger; 2005. p.764-76.

2. Piermattei DL, Flo GL. Manual de ortopedia e tratamento das fraturas dos pequenos animais. São Paulo: Manole; 1999.

3. Alvarenga J, D' Oliveira KS. Movimento cranial de gaveta positivo. São Paulo; 2005. [Apostila do Curso de Atualização em Cirurgia Ortopédica em Animais de Pequeno Porte- CIPO].

4. Chierichetti AL, Alvarenga J, Pedro CR, Stopiglia AJ. Ruptura de ligamento cruzado cranial. Estudo comparativo da técnica extracapsular com enxerto autógeno de fáscia lata com e sem artrotomia exploratória. Clin Vet. 2001; 6(1):34-42.

5. Romano L, Pereira CAM, Schmaedecke A, Saut JPE, Ferrigno CRA. Análise biomecânica do joelho íntegro e com ruptura do ligamento cruzado cranial quanto o grau de deslocamento cranial e rigidez articular em cães. Acta Cir Bras. 2006; 21(1):46-50.

6. Lafaver S, Miller NA, Stubbs WP, Taylor RA, Boudrieau RJ. Tibial tuberosity advancement for stabilization of the canine cranial cruciate ligament-deficient stifle joint: surgical technique, early results, and complications in 101 dogs. Vet Surg. 2007; 36(6):573586.
7. Voss K, Damur DM, Guerrero T, Haessig M, Montavon PM. Force plate gait analysis to assess limb function after tibial tuberosity advancement in dogs with cranial cruciate ligament disease. Vet Comp Orthop Traumatol. 2008; 21(3):243-9.

8. Selmi AL, Lins BT, Selmi GRB, Mendes GM. Centro instantâneo de movimento, na avaliação ex-vivo da reconstrução extra-articular fabelo-tibial, após transecção do ligamento cruzado cranial em cães. Cienc Rural. 2003; 33(5):875-80

9. Muzzi LAP, Rezende CMF, Muzzi RAL, Borges NF. Ruptura do ligamento cruzado cranial em cães: fisipatologia e diagnóstico. Clin Vet. 2003; 46(1):32-42.

10. Alvarenga J, Vianna RS, Pinto Junior RS. Ruptura do ligamento cruzado no cão. Sindesmoplastia extra-articular com centro frênico de eqüino conservado em glicerina [Apresentado XV Congresso Brasileiro da Anclivepa; 1985; Rio de Janeiro]

11. Tomlinson J, Constantinescu GM. Two methods for repairing ruptures of the cranial cruciate ligament in dogs. Vet Med. 1994; 89(1):32-41.

12. Muzzi LAP, Rezende CMF, Muzzi RAL, Borges NF. Ruptura do ligamento cruzado cranial em cães: fisiopatologia e diagnóstico. Clin Vet. 2003; 46(1):32-42.

13. Selmi AL, Padilha Filho JG, Lins BT, Mendes GM, Eimantas GC. O centro instantâneo de movimento e vetor de velocidade em joe- 
Ihos submetidos a incisuro plastia troclear e estabilização articular após transecção do ligamento cruzado cranial em cães. Cienc Rural. 2007; 37(3):777-83.

14. Schwandt CS, Bohorquez-Vanelli A, Tepic S, Hassig M, Dennler R Vezzoni A, Montavon PM. Am J Vet Res. 2006; 67(11):1855-60.

15. Stein S, Schmoekel $H$. Short-term and eight to 12 months results of a tibial tuberosity advancement as treatment of canine cranial cruciate ligament damage. J Small Anim Pract. 2008; 49(8):398404.

16. Dennler R, Kipfer NM, Tepic S, Hassig M, Montavon PM. Inclination of the patellar ligament in relation to flexion angle in stifle joints of dogs without degenerative joint disease. Am J Vet Res. 2006; 67(11):1849-54.

17. Aiken SW, Bauer MS, Toombs JP. Extraarticular fascial strip repair of the cranial cruciate deficient stifle: technique and results in seven dogs. Vet Comp Orthop Traumatol. 1992; 5:145-50.

18. Piermattei DL, Flo GL. Manual de ortopedia e tratamento das fraturas dos pequenos animais. São Paulo: Manole; 1999. p. 496513.

19. Dikinson CR, Nunamaker DM. Repair of ruptured anterior cruciate ligament in the dog: experience of 101 cases, using a modified fascia strip technique. J Am Vet Med Assoc. 1977; 170(8):827-30.

20. D'Oliveira KS, Alvarenga J. Reparação Cirúrgica extra-articular da ruptura do ligamento cruzado cranial de cão (canis familiaris) com centro frênico heterólogo preservado em glicerina. Cienc Anim Bras. 2000; 1:107.

21. Pichler ME, Bacon JP, Evans JA. The fascia lata as a replacement for the cranial cruciate ligament: two new surgical techniques. J Am Anim Hosp Assoc. 1982; 18:779-84.

22. Banks WJ, Piermattei DL, Wykes PM. et al. Histological characteristic of fascia lata implants in a synovial environment. Anat Histol Embryol. 2007; 14(1):79-80.

23. Penha EM, Rezende CMF, Melo EG, Doretto JV, Araújo FA, Vieira NT. Pós-operatório tardio da substituição do ligamento cruzado cranial no cão. Arq Bras Med Vet Zootec. 2007; 59(5):1184-93.
24. Kennedy JC, Roth JH, Mendenhall HV, Sanford J. Intraarticular replacement in the anterior cruciate ligament-deficient knee. Am J Sports Med. 1980; 8(1):1-8

25. Gomes JLE, Marczyk LRS. Reconstrução dos ligamentos cruzados do joelho com tendão duplo do semitendinoso. Rev Bras Ortop. 2004; 39(4):137-46

26. Camanho GL, Viegas AC. Avaliação da reconstrução do ligamento cruzado anterior em pacientes com idade acima de 45 anos. Rev Bras Ortop. 2001; 36(1):37-40

27. Paccola CAJ, Kfuri Jr M, Cunho PSA, Foraginolo F. Reconstrução do joelho com ligamento patelar: analise comparativa do ligamento autólogo versus homólogo. Acta Ortop Bras. 2000;8(4):202-8.

28. Buquera EC, Canola JC, Filho, JGP, Furlani JM, Talieri IC, Selmi AL. Radiografia e macroscopia do joelho após estabilização extra-articular utilizando fáscia lata, fio de poliéster trançado ou fio de poliamida para correção da ruptura do ligamento cruzado cranial em cães. Cienc Rural. 2002; 32(1):73-8.

29. Oliveira ST, Raizer AG, Guedes AGP. Reparação do ligamento cruzado cranial em cães por tendão homólogo conservado em glicerina e associado a fio de náilon. Cienc Rural. 2003; 33(24):717-23.

Recebido em 07/10/2008

Aceito para publicação em 09/12/2008

Conflito de interesse: nenhum

Fonte de financiamento: nenhuma

\section{Como citar esse artigo:}

Ferreira ML, Schanaider A, Silva PC, Abreu AV, Costa AFN, Braga JM, Rousso Filho R, Pereira LPM. Estudo da técnica da sindesmoplastia extra-articular com fascia lata autógena. Modelo em case. Rev Col Bras Cir. [periódico na Internet] 2009; 36(2). Disponível em URL: http:/ /www.scielo.br/rcbc

\section{Endereço para correspondência:}

Manoel Luiz Ferreira

E-mail: louiz_25@yahoo.com.br 